\title{
Inhalation injury and burn trauma: an experimental investigation of oxidative stress and histopathology
}

\author{
Ghada A. Eshak*, Khaled A. Nasef**
}

Forensic Medicine \& Clinical Toxicology Department*, Biochemistry Department* Faculty of Medicine- Minia University, Egypt

\begin{abstract}
Smoke inhalation injury is associated with high incidence of pulmonary complications as it represents a major cause of mortality after major burn injury. Burn is associated with release of inflammatory mediators which ultimately cause local and distant pathophysiological effects. The present study investigated the effect of smoke inhalation orland burn injury on the antioxidants status in the lungs in a rat model to simulate an inhalation injury as might be encountered by firefighters and burn victims. Seventy five rats were equally randomized to five groups: Sham group, smoke inhalation injury group, burn group, sham burn group, and smoke burn group. At the end of the exposure protocol rats were killed by cervical decapitation and the lungs were removed completely and processed for histopathological and biochemical analysis by measuring lung antioxidant enzyme activities: Malondialdehyde (MDA), superoxide dismutase (SOD) and glutathione peroxidase (GPs) level, as an index of lipid peroxidation. Grossly, results showed that rats'lungs in the smoke inhalation group and the smoke burn group showed multiple hemorrhagic spots. Light microscopic examination showed localized and diffuse alveolar hemorrhage. Two rats in the burn group had evidence of pneumonia and lung abscesses. Biochemically results showed that both smoke inhalation and burn injury significantly elevated lung MDA and glutathione peroxidase levels when compared with controls. The combined smoke and burn group resulted in a more significant rise in both antioxidant levels indicating a higher level of lipid peroxidation. SOD level was significantly lowered on exposure to both conditions when compared to control. SOD level was significantly lower in the combined injury group when compared to either smoke or burn alone. In conclusion; the above data provide evidence that inhalation injury with and without burn decrease tissue antioxidant capacity and increase tissue peroxidative injury.
\end{abstract}

Keywords:

Smoke inhalation injury; burn injury; experimental models; oxidative stress.

\section{INTRODUCTION}

Smoke inhalation injury is generally defined as inhalation of thermal or chemical irritants [1]. It is a major co-morbid factor which might be encountered by firefighters and injured burn victims [2]. Inhalation injury reportedly accounts for $20 \%-84 \%$ of the mortality in burned individuals and is associated with higher mortality rates for every age and burn size category [3]. Mortality rates for combined major burn injury and inhalation injury exceed that of either injury alone [4].

Respiratory complications resulting from smoke inhalation are the major cause of morbidity and mortality in victims of fires. Smoke associated with structural fires arises from the combustion or pyrolysis of wood and the various natural and synthetic fabrics, plastics, and other common materials available [3].

Because of the complexity of smoke inhalation and the likelihood of other burn injuries, no ideal animal model exists nowadays. The majority of studies in experimental animals have employed large animals, such as sheep, where the animal is anesthetized, and smoke is introduced by mechanical ventilation [5]. Although use of these animals has contributed much to understanding of smoke inhalation injury, a few studies have investigated smoke inhalation in a small animal, such as a rodent [2].

Thermal trauma may cause damage to multiple organs distant from the original burn wound and may lead to multi-organ failure. Thermal injury is accompanied by complex events that exert deleterious effects on various organs in different systems distant from the original burn wound. Although the pathophysiological mechanisms of tissue injury remains unclear, there is increasing evidence that both oxidative and nitrosative stress have an important role in the development of multi-organ failure after thermal injury [6].

Reactive oxygen species (ROS) are mediators of chronic tissue damage. Endogenous antioxidants may increase in response to oxidants release and act as mediators to reduce tissue injury [7]. The influence of mediators in inhalation and/or burn injury has not been thoroughly investigated. While burn resulted in increased concentrations of lipid peroxides in systemic circulation [8,9] and in cardiac tissue [2,10]; a little is known about lipid peroxidation and oxidative stress in the lungs; so this work aimed to detect the effect of smoke inhalation or $\backslash$ and burn injury on the lung antioxidant response as an index of oxidative stress and lipid peroxidation in a rat model.

\section{MATERIAL AND METHODS:}

\section{Animals}

Seventy five adult albino rats (with mean body weight of $180 \pm 20 \mathrm{gm}$.) were obtained and housed in the Faculty of Medicine, Minia University, at temperature controlled rooms, and 12-h light:12-h dark cycle. The animals were maintained on an unrestricted standard diet with free access to tap water for 1 week before the experiments for acclimatization. All procedures were done in accordance to the principles of laboratory animal care and guidelines and with approval of the Minia Faculty of Medicine Ethical Committee. 


\section{The inhalation protocol:}

We used a self-designed apparatus consisting of a combustion chamber and an exposure chamber. A stainless steel combustion chamber with a dimension of $60 \times 50 \times 40 \mathrm{~cm}$ was designed to generate smoke, and fitted to its upper surface was an electic respirator (Mizol inc. Company, China) for sucking the generated vapors to an attached rubber tube of $2 \mathrm{~cm}$ diameter for delivering smoke into the exposure chamber. The exposure chamber was made of wood and had an upper sliding glass side to enable observation of the rats during exposure and easily opened to allow free delivery of air after each exposure cycle. The smoke inhalation injury protocol was performed according to [11]. Smoke was generated by slowly smoldering wood shavings ( $120 \mathrm{~g} / \mathrm{kg}$ body weight) mixed with $30 \mathrm{ml}$ kerosene in a stainless steel basin before use.

Each animal was anesthetized with an intraperitoneal injection of ketamine "Sigma company" ( $90 \mathrm{mg} / \mathrm{kg})$. Seventy five adult albino rats were divided into five equal groups (15 rats each): Group 1 (sham smoke group) served as a control. Rats in this group were kept in the smoke exposure room subjected to the same smoke exposure protocol as in group 2 but without actual smoke exposure. Group 2 (smoke exposed group) rats were kept in the exposure room exposed to successive 9 min. periods of smoke which were separated into three times by 30 second exposures to ambient air $(3 \mathrm{~min}$. smoke exposure followed by 30 second exposure to fresh air repeated thrice [12]. Group 3 (burn group); according to [13], a section on the back of each rat, corresponding to $20 \%$ of the total body surface area (TBSA) was shaved. Rats then received a full thickness scald by means of a metal bar screwed to a screw driver. The bar was heated over a Bunsen burner for 2 min then was held in contact with the shaved animal skin for 20 seconds, producing thirddegree burns. Body surface was calculated by Meeh's formula: $A=10 \times W^{2 / 3}$, where: $A=$ area in $\mathrm{cm}^{2}, 10$ is a constant and $W=$ weight in grams [14]. Group 4 (sham burn group) rats treated as in group 3 but with non-heated metal bar and Group 5 (burn smoke group) where rats were burnt as in group 3 then exposed to smoke as in group 2. Burnt rats were then treated with standard measures for burn wound care. $48 \mathrm{~h}$ after treatment, the rats were killed by cervical decapitation and the lungs were removed and processed for measurement of malondialdehyde (MDA), superoxide dismutase (SOD) and glutathione peroxidase (GPs) levels.

\section{METHODS OF BIOCHEMICAL ANALYSIS:}

- Malondialdehyde levels (MDA) in lung tissue were measured by thiobarbituric acid assay according to [15]; two $\mathrm{g}$ of the left lower lobe were homogenized in $5 \mathrm{ml} 1 \%$ (wt/vol) meclofenamate solution and centrifuged. $0.5-\mathrm{mL}$ aliquots of the sample were added to $4 \mathrm{~mL}$ trichloroacetic acid-thiobarbituric acid-hydrochloric acid reagent (TCATBA-HCl) and to $4 \mathrm{~mL}$ TCA-TBA-HCl+ butylated hydroxytoluene (BHT) A flocculent precipitate was removed by centrifugation at 1000 R.P.M. for 10 minutes. Absorbance, corrected for reagent blank, was measured by spectrophotometer (Shimadzu, UV-2401PC, Australia) at $535 \mathrm{~nm}$ according to the following formula: $\mathrm{MDA}$ ( $\mathrm{mmol} / \mathrm{mL}$ sample) $=\mathrm{A}_{535} \mathrm{~nm}$ $\times(1 / 156) \times 2$, where $A_{538} \mathrm{~nm}=$ absorbance of sample, corrected for blank and $156 \mathrm{mmol}^{1} \mathrm{~cm}^{1}=$ extinction coefficient of MDA.

- Superoxide dismutase (SOD): Colorimetric method according to [16] was used to measure SOD level by spectrophotometer (Shimadzu, UV2401PC, Australia). One g of lung tissue was perfused with phosphate buffer saline (PBS) solution at $\mathrm{pH} 7.4$, homogenized in $5 \mathrm{ml}$ cold buffer (50mM potassium phosphate) then centrifuged at 4000 R.P.M. for $15 \mathrm{~min}$. The supernatant was used to for measurement.

- Test Principle: The Oxis SOD $-525^{\mathrm{TM}}$ method (Oxis Company, U.S.A.) was based on the SOD-mediated increase in the rate of autoxidation of 5,6 , 6a, 11b-tetrahydro-3, 9, 10-trihydroxybenzo[c] flourene R1 in aqueous alkaline solution to yield a chromophore with maximum absorbance at $525 \mathrm{~nm}$.

- Glutathione peroxidase (GP) was determined spectrophotometrically (Shimadzu, UV-2401PC, Australia) according to [17] by following the oxidation of NADPH to NADP which is accompanied by a decrease in absorbance at $340 \mathrm{~nm}$ (A340).

\section{STATISTICAL ANALYSIS:}

Data were analyzed with SPSS (Statistical Software for Social Sciences, ver. 12. 0, SPSS Inc., Chicago, IL). Results were presented as mean \pm SE. Data for biochemical test results (MDA, SOD and GP) for the five groups were compared through two-way analysis of variance (ANOVA). A Tukey posthoc test was applied to compare the group means. $P<0.05$ was considered statistically significant.

\section{RESULTS:}

No deaths were encountered during experimentation and all rats survived till scarification. Gross examination of the lungs on dissection revealed multiple localized and diffuse lesions. Macroscopic lesions were clearly observed in all rats of both smoke exposed group (Group 2) and burn smoke group (group 5). Lesions were consistent with hemorrhage. The lungs were firm with localized and diffuse hemorrhagic spots and petechiae over the lung surface. Hemorrhage occurred under the visceral pleura and was oval and rounded, dark-red in color. Hemorrhage extended into the subjacent lung (Figure 1, 2). Hemorrhage was more extensive in group 5 occupying nearly a whole lung lobe (Figure 3). Moreover, two rats in group 5 had multiple lung abscesses (Figure 4).

Histopathologic examination revealed prominent intra-alveolar hemorrhage where numerous RBCs were extravasated in the alveolar spaces (Figure 5,6$)$ and lung abscess with dense inflammatory cell infiltrate was observed. The inflammatory cells are predominantly lymphocytes (Figure 7).

Lung MDA concentrations were determined in all groups as a lipid peroxidation index. A significant difference in MDA levels was found between tested groups ( $F=172.363, p=0.000)$. Lung MDA level showed significant increase in rats of smoke exposed group (group 2) and burn group (group 3) when compared with the control group $(p=0.000)$. The highest level of MDA was obtained in smoke burn group (group 5) with a mean value of (16.32 \pm $0.94 \mathrm{nmol} / \mathrm{g})$ with a significant difference $(P=0.000)$ when compared with control. The mean values of MDA are illustrated in Table 1 \& Figure 8.

Results also revealed significant difference in SOD levels among studied groups ( $F=107.546, p=0.000$ ). SOD lung levels decreased in smoke exposed group, burn group and smoke burn group compared to control $(p<0.05)$. Smoke inhalation resulted in significant decrease in SOD level than burn trauma alone (mean $=0.16, p=0.000$ ) while combined smoke burn exposure 


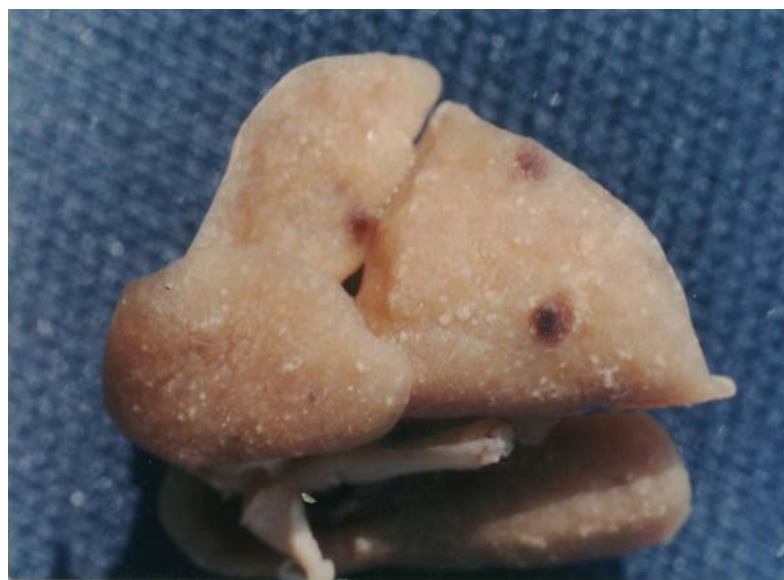

Figure 1. Localized multiple hemorrhagic spots in lung of rat in smoke exposed group.

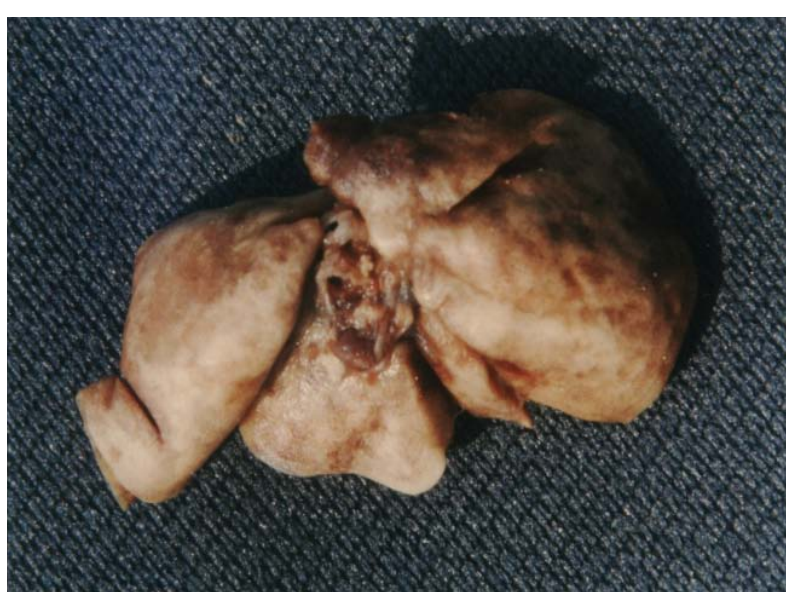

Figure 2. Diffuse multiple hemorrhagic spots occupying large area in lung of rat in smoke exposed group.

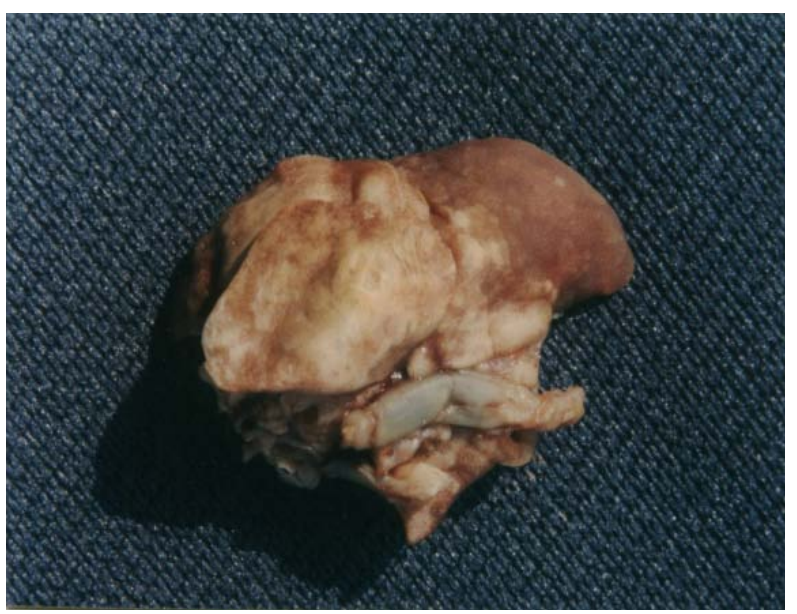

Figure 3. Diffuse hemorrhage involving nearly a whole lung lobe of a rat in burn smoke exposed group.

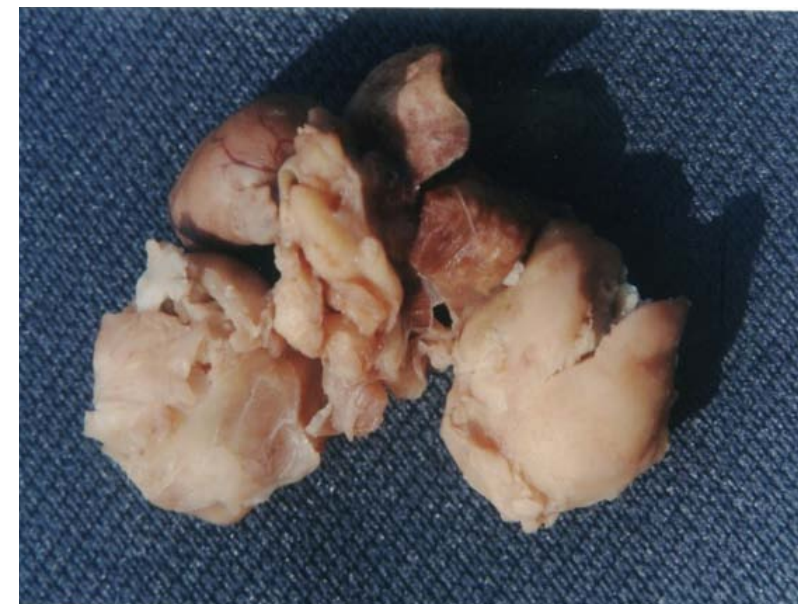

Figure 4. Multiple lung abscesses in lung of a rat in burn smoke exposed group.

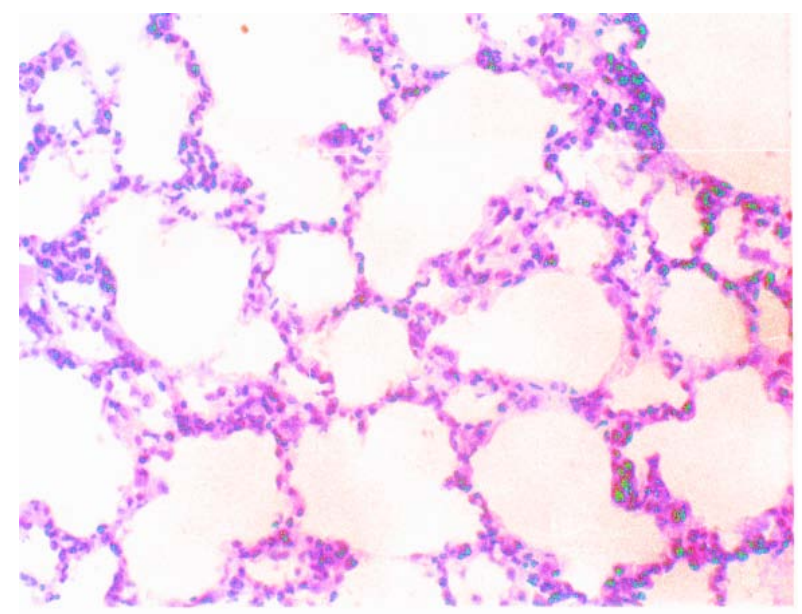

Figure 5. Photomicrograph of control lung from sham smoke group shows the normal histological picture. ( $\mathrm{H} \& \mathrm{E} ; \mathrm{X} 400)$.

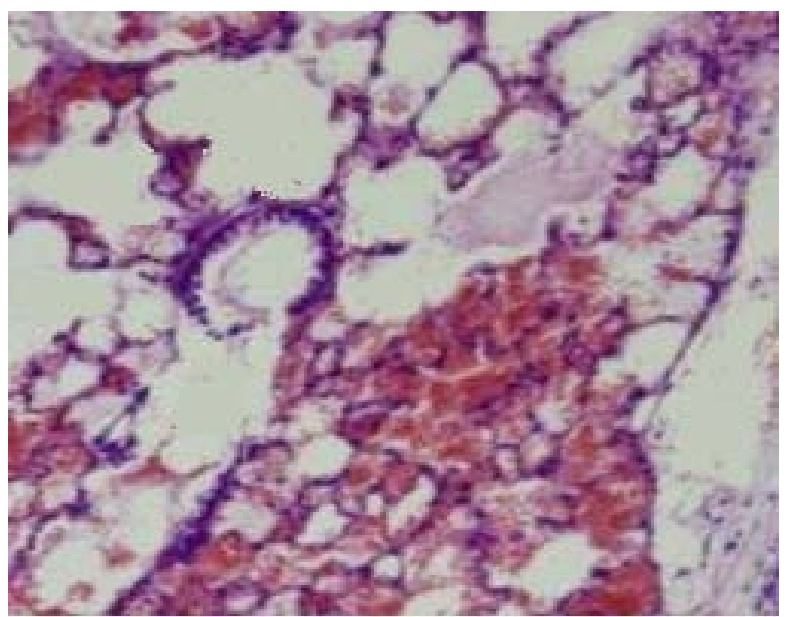

Figure 6. Photomicrograph of rat's lung from smoke inhalation group showed intr-alveolar hemorrhage $(H \& E ; X 400)$. 
resulted in more significant deterioration in SOD level. The mean levels of SOD among different studied groups are presented in Table 1 \& Figure (9).

Glutathione peroxidase levels were significantly changed in animals' lungs of various treated groups $(F=196.185, p=0.000)$. Smoke inhalation and burn injury significantly elevated lung glutathione peroxidase levels after injury when compared with control $(p=0.000)$. No significant difference was found in SOD level between smoke inhalation and burn injury group $(p=0$. 865). GP levels were significantly higher in the combined injury group when compared to either smoke or burn alone (mean 4.5500, $p=0.000$, mean 4.4300, $\mathrm{P}=0.000$ ). Table $1 \&$ Figure (10).

\section{DISCUSSION}

Smoke inhalation injury, either by itself or in the presence of a burn, is wellrecognized to result in severe lung-induced morbidity and mortality. The most common cause of death in burn centers is respiratory complication and consequently failure [18]. Inhalation injury was recorded in $51.47 \%$ patients

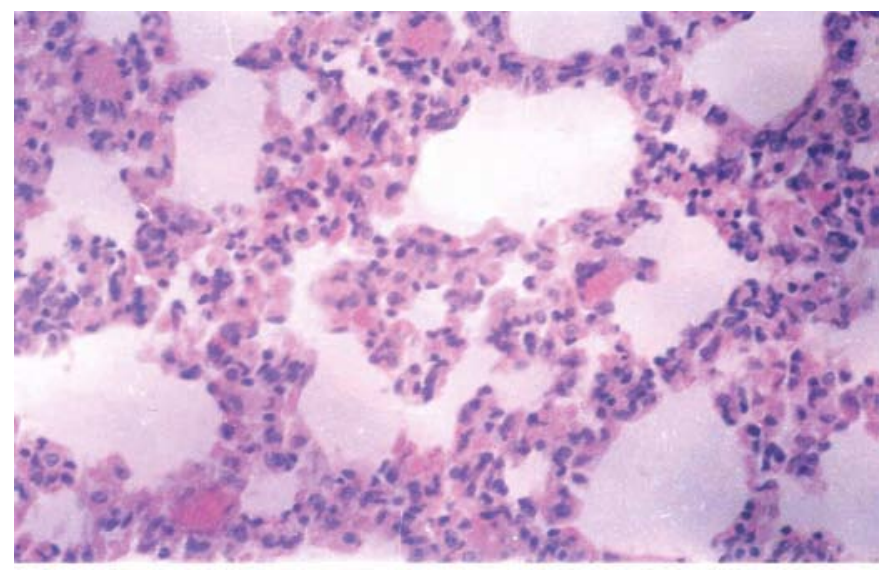

Figure 7. Photomicrograph of lung from smoke burn group shows multiple focuses of pneumonites $\uparrow$ and lung abscess $\uparrow \uparrow$. A mixed picture of interstitial (alveolar wall) and intraalveolar wall inflammation. Predominant cells are lymphocytes and plasma cells (H\&E; X 400).

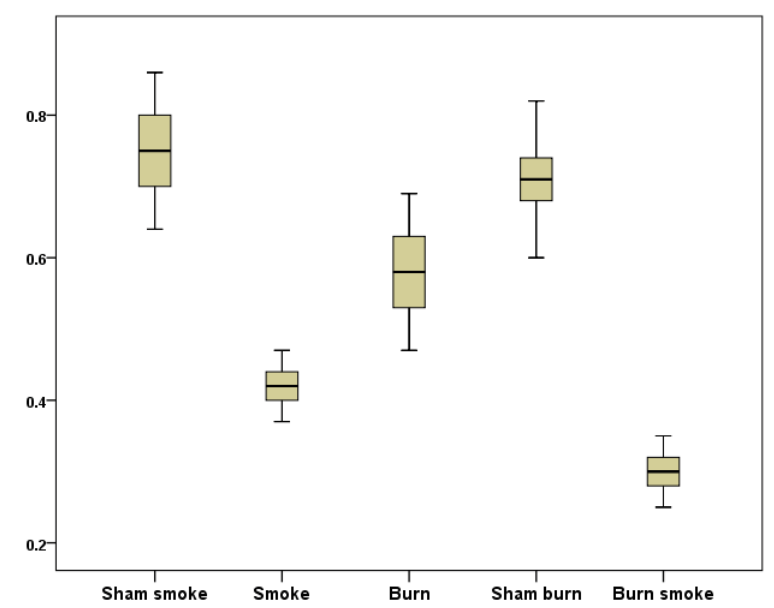

Figure 9. Boxplot of lung SOD level in different studied groups.
Table 1. Mean values of malondialdehyde (MDA), superoxide dismutase (SOD) and glutathione peroxidase levels (GP) among studied groups.

\begin{tabular}{|c|c|c|c|c|c|c|}
\hline \multicolumn{2}{|c|}{ Groups } & Group 1 & Group 2 & Group 3 & Group 4 & Group 5 \\
\hline $\begin{array}{c}\text { Parameter } \\
\text { MDA }\end{array}$ & Mean & 8.53 & 15.51 & 11.52 & 9.31 & 16.32 \\
\cline { 2 - 7 } & S.D. & 0.79 & 0.97 & 1.34 & 1.82 & 0.94 \\
\hline $\begin{array}{c}\text { SOD } \\
\text { U/mg }\end{array}$ & Mean & 0.75 & 0.42 & 0.58 & 0.71 & 0.30 \\
\cline { 2 - 7 } & S.D. & 0.114 & 0.049 & 0.057 & 0.112 & 0.050 \\
\hline \multirow{2}{*}{ U.g tissue-1 } & Mean & 26.09 & 38.12 & 37.24 & 26.90 & 41.76 \\
\cline { 2 - 7 } & S.D. & 0.21 & 1.21 & 1.05 & 1.03 & 0.99 \\
\hline
\end{tabular}

Group 1: Sham smoke group. Group 3: Burn group. Group 5: Burn smoke group
Group2: Smoke exposed group Group 4: Sham burn group. S.D.: standard deviation.

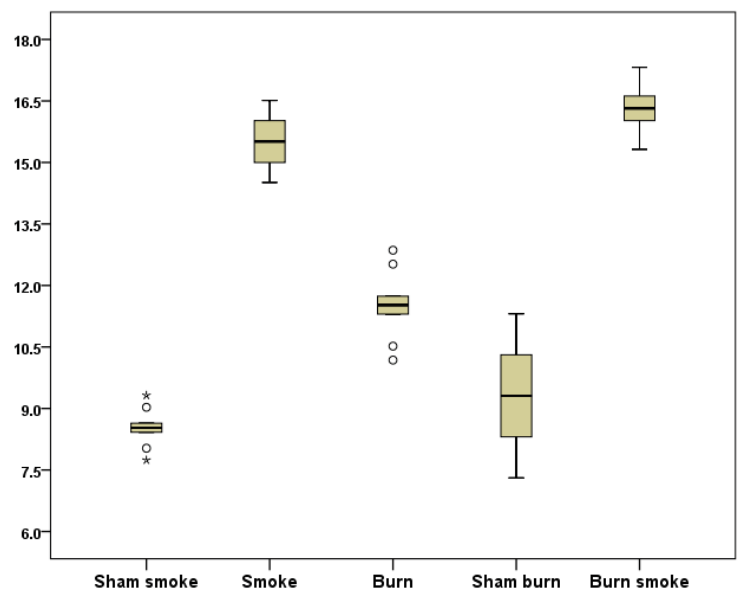

Figure 8. Boxplot of lung MDA level in different studied groups.

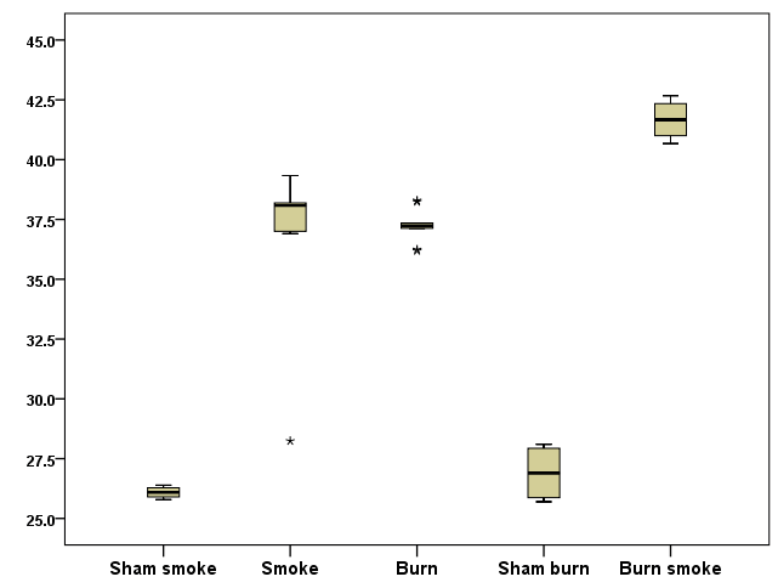

Figure 10. Boxplot of lung GP level in different studied groups. 
who suffered flame burns in closed space [19]. The death rate for patients with inhalation injuries was $69.90 \%$ compared to $6.45 \%$ in patients without inhalation injury, emphasizing that inhalation injury is a predictive factor in mortality of burns [20]. Although the exact mechanism for respiratory complications of inhalation injury and/or burn has not been defined, different mechanisms are postulated by many authors; [21] \& [22] attributed them to a combination of thermal, hypoxaemic and chemical effects of smoke. Billi et al., [3] mentioned the role of neutrophil implicated acute inflammatory process, while [23] reported the role of carbon monoxide, noxious gases and free radical generations; so this work was designed to detect the effect of smoke inhalation injury or $\backslash$ and burn on lung histopathology and on antioxidants levels.

Histopathologic examination of the lungs in smoke exposed and burn smoke group revealed intra-alveolar hemorrhage, pneumonia and lung abscess was consistent with tissue injury after smoke inhalation and burn injury mentioned in literatures [3,24-26]. Polymorphic nuclear leucocytes, particularly neutrophils are the primary mediators for the resultant acute inflammatory lung parenchymal damage as reported by Gute et al., [27]. Thom et al. [28] also suggested that systemic stress may trigger parencyhmal injuries. Mortality was prevented by performing intermittent smoke and fresh air inhalation in concordance in the literature.

Our results demonstrated that smoke inhalation orland burn thermal injury increases the oxidative stress and consequently tissue damage. This is evidenced by the increase in MDA levels which indicate an inflammatory process due to oxidant generation, reduction in SOD level which has an antioxidant effect and elevated GP level. These findings agree with [8,20,29-32]. MDA is generated from reactive oxygen species (ROS) through degradation of polyunsaturated lipids and is assayed in vivo as a bio-marker of oxidative stress [33], while SOD offers first line of defense against the superoxide radicals. It is one of the most important intracellular antioxidant enzymes, which has an antitoxic effect against superoxide anions that causes impairment to macromolecules like proteins, lipids, carbohydrates and nucleotides [34].

Oxidant generation is part of normal metabolism of many types of cells. To protect itself against exposure to noxious oxidants the lung has a well-developed antioxidant system [35]. Oxidative stress that occurs in the cells, because an imbalance between the prooxidant/antioxidant systems, causes injure to biomolecules such as nucleic acids, proteins, structural carbohydrates, and lipids. Among these targets, the peroxidation of lipids is basically damaging because the formation of lipid peroxidation products leads to spread of free radical reactions [36]. Another theory for free radical generation was hypothesized by Horton, [8] who found that after thermal trauma, all tissues are subjected to ischemia which followed by reperfusion injury. Consequently, several oxidative and nitrosative stresses initiate an inflammatory cascade. Activated inflammatory cascade causes local and systemic neutrophil sequestration, which is source of reactive oxygen species and reactive nitrogen species [6].

The observed rise in GP with its antioxidant property was as a defense mechanism from body to counter the excess ROS production; however, a high production of oxygen radicals evidenced by excess MDA with decreased antioxidant level of SOD may exceed the detoxification capacity of GP as an antioxidant enzyme [37]. Glutathione peroxidases (GPs) are the major enzymes in the antioxidative defense mechanism depending on glutathione [38]. They scavenge hydrogen peroxide in the presence of reduced glutathione [39]. They also act as a substrate in other detoxifying enzymes against oxidative stress, such as glutathione transferases. It participates in amino acid transport through the plasma membrane, scavenges hydroxyl radical and singlet oxygen directly, detoxifying and lipid peroxides by the catalytic action of GPX [40]. We also found that combination of smoke injury with body surface burn can markedly increase the oxidative stress and hence the respiratory complications compared with burn alone which is compatible with Belli et al., [3]. The chemical properties of smoke combined with burn injury induce more inflammatory response, a higher vascular permeability, and pulmonary edema [41].

\section{SUMMARY:}

Smoke inhalation injury is a threat to personnel who injured in enclosed spaces. Smoke inhalation injury continues to exert an additive effect on the morbidity and mortality of patients with cutaneous burns. The above data provide abundant evidence that inhalation injury and/or burn produces abundant free radicals and decrease tissue antioxidant capacity and increase tissue peroxidative injury.

\section{REFERENCES}

[1] Rehberg S., Maybauer M., Enkhbaatar P., Maybauer D., Yamamoto Y. and Traber D.L. Pathophysiology, management and treatment of smoke inhalation injury. Expert Rev Respir Med, (2009); pp. 283-297.

[2] Dubick M.A., Carden S.C. Jordan B.S., Paulette C. L. and David W M. Indices of antioxidant status in rats subjected to wood smoke inhalation and/or thermal injury. Toxicology, (2002); 1 (176), pp. 145-157.

[3] Belli S., Ozgur B., Handan O., Suna T., Gülten K., Altug K., Hamdi K. and Haberal M. Protective role of simvastatin on lung damage caused by burn and cotton smoke inhalation in rats. Journal of Surgical Research, 2011; 167 (2), pp e283e290.

[4] Ken M. and Andrew C. Acute inhalation injury. Emerg Med Clin N Am. (2003); 21, pp. 533-557.
[5] Park M.S., Cancio L.C., Jordan B.S., Brinkley W.W., Rivera V.R. and Dubick M.A. Assessment of oxidative stress in lungs from sheep after inhalation of wood smoke. Toxicology, (2004); 15 (195), pp. 97.

[6] Dinçer A., Hakan T., Lilüfer T., Handan Ç., Hakan Ö., Candan Ö., Selim A. Protective effect of trapidil against oxidative organ damage in burn injury. Burns, 2005:31 (7), pp859-865.

[7] Suzy A., Marc J., Percy B., Jeffrey H. and Serpil E. Increased glutathione and glutathione peroxidase in lungs of individuals with chronic beryllium disease. Am. J. Respir. Crit. Care Med. 1999; 159 (6), pp.1824-1829.

[8] Horton J.W: Free radicals and lipid peroxidation mediated injury in burn trauma: the role of antioxidant therapy. Toxicology, (2003); 189 (1-2), pp. 75-88.

[9] Katsumi S., Hiroaki N., Maret G., Daniel L.T., Motohiro N. Plasma and tissue vitamin Edepletion in sheep with burn and smoke inhalation injury. Burns, 2008; 34 (8), pp. 1137-1141. 
[10] Toon M., Maybauer M., Greenwood J., Maybauer D .and Fraser J. Management of acute smoke inhalation injury. Critical Care and Resuscitation, 2010; 12(1), pp. 53-61.

[11] Xiaochen Q., Shizhao J., Junjie W., Hengyu L., Ting X., Bohan P., Shichu X. and Zhaofan $X$. The therapeutic efficacy of Ulinastatin for rats with smoking inhalation injury. International Immunopharmacology, 2012; 14 (3), pp. 289-295.

[12] Zhu F., Qiu X., Wang J., Jin Y, Sun Y, LvT. and Xia Z. A rat model of smoke inhalation injury. Inhal Toxicol, 2012; 24, pp. 356-364.

[13] Meyer T.N. \& Silva A.L. A standard burn model using rats. Acta Cirurgica Brasileira, 1999; 14(4), Available from URL: http://www.scielo.br/acb.

[14] Gilpin D.A. Calculation of a new Meeh constant and experimental determination of burn size. Burns, 1996; 22, pp. 607

[15] Buege A. \& Aust S. Microsomal lipid peroxidation. Methods Enzymol, 1978; 52, pp 302-310.

[16] Nebot C. Spectrophotometric assay of SOD activity based on the activated autoxidation of a tricyclic catechol. Analytical Biochemistry,1993; 214,pp. 442451.

[17] Lawrence R. A. \& Burk R.F. Glutathione peroxidase activity in selenium-deficient rat liver. Biochem. Biophys. Res. Commun., 1976; 71, pp. 952-958.

[18] Robert H. D. Smoke Inhalation Lung Injury: An Update. An open access journal. www.e-plasty.com. Last visited December, 2012.

[19] Çetin C., Özyilmaz M., Bayçu C., . Köse A. and Karabağli Y. Effects of rolling inhibition on smoke inhalation injury. Burns, 2003; 29(4), pp. 307-314.

[20] Florea P. \& Corbea C. Assessment of pulmonary dysfunction at large burnt. Doctoral thesis, 2009; University of medicine and pharmacy. CRAIOVA. Available at www.umfcr.ro.

[21] Stewart R.J., Yamaguchi K.T., Knost P.M., Mason S.W., Roshdieh B.B., Samadani S and Chang B.L. Effects of ibuprofen on pulmonary oedema in an animal smoke inhalation model. Burns, 1990; 16, pp. 409-413.

[22] Guy J.S. \& Peck M.D. Smoke inhalation injury: pulmonary implications. Respir. Care, 1999; 3, pp. 904-912.

[23] Lee H., Greeley G. and Englande E. Transgenic overexpression of neuroglobin attenuates formation of smoke-inhalation-induced oxidative DNA damage, in vivo in the mouse brain. Free Radical Biology and Medicine. 2011; 51 (12), pp. 2281 2287.

[24] Nash G., Foley F.D. and Langlinais P.C. Pulmonary interstitial edema and hyaline membranes in adult burn patients. Electron microscopic observations. Hum Pathol. 1974; 5, pp. 149

[25] Ahn S.Y., Sugi K. and Talke P. Effect of allopurinol on smoke inhalation in the ovine model. J Appl Physiol. 1990; 68, pp. 228

[26] Hubbard G.B., Langlinais P.C. and Shimazu T. The morphology of smoke inhalation injury in sheep. J Trauma. 1991; 31, pp. 1477.
[27] Gute D.C., Ishida T., Yarimizu K. and Korthuis RJ. Inflammatory responses to ischemia and reperfusion in skeletal muscle. Mol. Cell. Biol., (1998); 179, pp. 169 187.

[28] Thom S.R., Mendiguren I., Winkle T.V., Fisher D. and Fisher A.B. Smoke inhalation with a concurrent systemic stress results in lung alveolar injury. Am. J. Respir. Crit. Care Med. (1994); 149, pp. 220-226.

[29] LaLonde C., Nayak U., Hennigan J.and Demling R. Excessive liver oxidant stress causes mortality in response to burn injury combined with endotoxin and is prevented with antioxidants. J. Burn Care Rehabil. 1997a; 18, 192-197.

[30] LaLonde C., Nayak U., Hennigan J. and Demling R. Plasma catalase and glutathione levels are decreased in response to inhalation injury. J. Burn Care Rehabil. 1997b; $18,515-519$.

[31] Cancio L.C \& Pruitt B.A. (2003): Inhalation injury "Ch.12" In: Basic and Clinical research in Military, Trauma, and Emergency Medicine edited by Tsokos G.C. \& Atkins J. P: 329, Human press Inc., Totowa, London, NJ.

[32] Rongjie Y., Xiaoling G ., Lin H., Zhixing Z., Huahua Z. The novel peptide PACAP-TAT with enhanced traversing ability attenuates the severe lung injury induced by repeated smoke inhalation. Peptides,2012; 38(1), pp. 142-149.

[33] Renée A.S., Teresa T. and Michael B.Z. Dairy attentuates oxidative and inflammatory stress in metabolic syndrome. Am J Clin Nutr. 2011; 94. pp. 422-430

[34] Mahaboob P. B. and Sujitha N. S. Chronic fluoride toxicity and myocardia damage: Antioxidant offered protection in second generation rats. Toxicol Int. 2011; 18(2).pp. 99-104.

[35] Papi A., Chicca M., Pandit A. and Caramori G. Oxidants and antioxidants Antioxidants, Nonenzymatic. Encyclopedia of Respiratory Medicine. 2006 pp. 266-271.

[36] Angel C. Lipid peroxidation of membrane phospholipids generates hydroxyalkenals and oxidized phospholipids active in physiological and/or pathological conditions. Chemistry and Physics of Lipids, 2009; 157(1), pp. 1-11.

[37] Antoni A., Pedro T., Emilia F., Josep A. T., Alfredo C. and Antoni P. Antioxidant response to oxidative stress induced by exhaustive exercise. Physiology \& Behavior, 2005; 84, pp.1 -7.

[38] Simona J., Joško O. and Janja M. Molecular impact of glutathione peroxidases in antioxidant processes. Biochemia Medica 2008; 18(2):162-74.

[39] Sung S. C., Min K., Byoung-Soo Y., Nam S. L., Ji W. P., In K. L., Yun S. L., Jae B. K., Young M., Hong K. L. and Kyong S. P. Glutathione Peroxidase 3 Mediates the Antioxidant Effect of Peroxisome Proliferator-Activated Receptor $\gamma$ in Human Skeletal Muscle Cells. Mol. Cell. Biol. 2009; 29 (1), pp 20-30.

[40] Valko M., Rhodes C.J. and Moncol J. Free radicals, metals and antioxidants in oxidative stress-induced cancer. Chem Biol Interact. 2006; 160(1), PP: 1-40.

[41] Enkhbaatar P. and Traber D. Pathophysiology of acute lung injury in combined burn and smoke inhalation injury. Clin Sci, 2004; 107, pp: 137- 143. 